\title{
Trade Protectionism and Intra-industry Trade: A USA - EU Comparison
}

\author{
Alexandra Ferreira-Lopes ${ }^{1}$, Cândida Sousa ${ }^{2}$, Helena Carvalho ${ }^{3} \&$ Nuno Crespo ${ }^{4}$ \\ ${ }^{1}$ Instituto Universitário de Lisboa (ISCTE - IUL), ISCTE Business School Economics Department, BRU - IUL \\ (BRU - Business Research Unit), Lisboa, Portugal, and CEFAGE - UBI. \\ ${ }^{2}$ AT - Tax and Customs Authority and Instituto Universitário de Lisboa (ISCTE - IUL), Portugal \\ ${ }^{3}$ Instituto Universitário de Lisboa (ISCTE - IUL), Department of Social Research Methods and CIES-IUL, Lisboa, \\ Portugal \\ ${ }^{4}$ Instituto Universitário de Lisboa (ISCTE - IUL), ISCTE Business School Economics Department and BRU - IUL \\ (Business Research Unit), Lisboa, Portugal \\ Correspondence: Alexandra Ferreira-Lopes, Instituto Universitário de Lisboa (ISCTE - IUL), ISCTE Business \\ School Economics Department, BRU - IUL (BRU - Business Research Unit), Lisboa, Portugal, and CEFAGE - UBI. \\ Av. Forças Armadas 1649-026, Lisboa, Portugal. Tel: 351-2-1790-3498.
}

Received: October 23, 2017

Accepted: November 15, 2017

Online Published: December 27, 2017

doi:10.5430/rwe.v8n2p88

URL: https://doi.org/10.5430/rwe.v8n2p88

\begin{abstract}
The aim of this work is to find patterns for products included in the customs tariffs of the USA and the EU (composed of over 5000 products disaggregated at the 6 digit-level) which share similarities, defined by a set of international trade variables, namely the index of revealed comparative advantages (RCA), the Grubel-Lloyd index, and other indicators of international trade. There is a strand in the literature advancing a theory that links the degree of intra-industry trade with the level of protectionism. In order to test this theory we use cluster analysis as a method of data analysis and the Grubel-Lloyd index as a classification variable between groups. For each of the analyzed regions we obtain four different groups. Thereafter each of these four clusters are further characterized with the help of the other international trade indicators and the tariffs. Finally, we establish a comparison between the two regions by examining possible differences and similarities. The results show a significant difference in the tariffs applied between the USA and the EU, with the USA presenting a lower level of protectionism. Additionally, the results for the USA show a positive relationship between the degree of intra-industry trade and a lower level of protectionism, while for the EU the results are not conclusive.
\end{abstract}

Keywords: trade policy, customs tariff, USA, EU, intra-industry trade, cluster analysis

JEL Codes: C38, F12, F13, F14

\section{Introduction}

The literature on trade protectionism has advanced a theoretical link, which has also been tested empirically, postulating that the level of trade protectionism is lower in countries that present a higher degree of intra-industry trade, i.e., if countries that are trading substitute goods (even though imperfect), engage in protectionist measures, they may more easily suffer retaliation, and so this type of trade is a "brake" on these protectionist measures.

This work aims to study the relationship between the degree of intra-industry trade and the level of trade protection in the USA and EU, two of the largest economic regions in the World. The degree of intra-industry trade in this work is measured by the Grubel-Lloyd (GL) index. This variable was used to perform a cluster analysis, which was then characterized using the information about tariffs, as well as additional indicators, built with data on exports and imports to and from the world for each of these regions. Cluster analysis has never been used to test this theory before.

Much of the literature on protectionism focuses on measuring the costs of applying protective measures and/or the degree of protectionism for each economy. The task of measuring the degree of protectionism (and costs) is very difficult, given the diversity of existing trade policy instruments. There are, however, several studies that seek to do so, as can be seen in Cipollina and Salvatici (2008). Traditionally, and given the difficulty, the trade policy instrument most commonly used to measure the degree of protection is the tariff, Ad valorem and specific. (Note 1) 
Empirical studies of this issue for the case of the USA and EU, respectively, can be found in the work of Hufbauer and Elliot (1994) and Messerlin (2001). The work of Bouët et al. (2008) provides a measure of protection, in percentage points, for several countries, including the USA and the EU. The results for the two countries in 2001 were, respectively, 2.3 and $3.1 \%$. This measure is lower, in both regions, for industrial goods, and higher for agricultural and textile goods. However, the USA is more protective vis-à-vis imports from developing countries, while in the EU protection is higher for imports from developed countries. For the year 2007, using an update of the same database - MacMap-HS6 - Guimbard et al. (2012) found for the USA and the EU, a total protection of 1.7 and $2.6 \%$, respectively. In this latest study the level of protection of the USA for agricultural goods and textiles increased slightly, while for industrial goods it decreased, also slightly. For the EU the protection for agricultural goods fell sharply, and the protection for industrial goods dipped slightly, with increased protection for textile goods.

The theory of tariff endogeneity claims that some macroeconomic variables and the country's own macroeconomic situation affect the degree of protectionism, i.e., the strength of tariffs varies with a given set of factors. These factors influence the setting of tariffs via pressure groups (lobbies) who seek to influence its value (Baldwin, 1985). Pioneering work of empirical verification of this theory can be found in Magee et al. (1989) and Bohara and Kaempfer (1991). The traditional microeconomic analysis on tariffs - via consumer, producer, and state surplus states that tariffs also have effects on prices, income, trade balance, and employment and unemployment rate by sectors, among others. Thus, there may be feedback effects between macroeconomic factors, the macroeconomic situation, and tariffs.

One of the factors that may affect the setting of tariffs is the predominant type of international trade of a country, i.e., if the composition of exports and imports are goods produced in different sectors - inter-industry trade, or if the composition of exports and imports are goods produced in the same sectors - intra-industry trade. Marvel and Ray (1987) find that in the presence of intra-industry trade, the degree of protectionism is lower, since the groups interested in the imposition of tariffs (the producers of substitute goods, who sell to the domestic market) would suffer retaliation from those who produce substitute goods to export, if effectively managed to increase protection. Thus, the existence of intra-industry trade promotes greater trade liberalization.

Greenaway and Hine (1991) analyze a priori the possible effects of the single European market, put into place in 1992. The authors show that in the 1980s, the growth trend in the weight of intra-industry trade of European countries that had occurred in previous decades, began to reverse, reviving a trend of increasing importance of inter-industry trade. The authors argue that if there is a predominance of this type of trade, the adjustment to the emergence of the single European market will be more severely felt by countries. Additionally, the very creation of the single market will bring an increase in the weight of this type of trade. The solution proposed was to eliminate barriers, especially non-tariff barriers imposed on the secondary sector, thereby promoting the exploitation of economies of scale, and increasing the importance of intra-industry trade, which has less severe consequences at the welfare level. When inter-industry trade is predominant, countries and sectors typically are characterized by specific production factors, and if they have no comparative advantage at the international level, will suffer almost unrecoverable welfare losses. Such an extreme case does not occur often at the level of intra-industry trade. The hypothesis that the weight of intra-industry trade decreased and the weight of inter-industry trade increased, in the decade preceding the entry into operation of the single European market, was confronted by Brülhart and Elliot (1998). Their results do not suggest that the effect hypothesized will happen in the years before 1992. However, the authors found evidence that high-technology industries with robust growth rates tend to have a higher proportion of intra-industry trade, while declining sectors tend to have a higher prevalence of inter-industry trade. The authors conclude that, since their results are mixed, the hypothesis that intra-industry trade brings along easier adjustments in situations such as the single European market has to be supported by a theoretical framework.

Clark (2002) performed an exercise similar to the two aforementioned studies (Greenaway and Hine, 1991 and Brülhart and Elliot, 1998), but for the USA, evaluating the effects of the North American Free Trade Association (NAFTA) for the period 1993-1998. The author used a sectoral breakdown, provided by the 3-digit Standard International Trade Classification (SITC), and concluded that the vast majority of the sectors analyzed increased the weight of intra-industry trade following the entry into operation of NAFTA, and in only nine sectors had that weight decreased, pointing to a minimally painful adjustment for the USA of the establishment of NAFTA. A study of Vogiatzoglou (2006) also about NAFTA for the period 1992-2002, corroborated the results of Clark (2002). Vogiatzoglou (2006) reached these conclusions, not only for the USA, but also for Canada and Mexico.

Ratnayake and Jayasuriya (1991) obtained results contrary to those described above, i.e., the effect of tariffs on intra-industry trade is significant, while the opposite is not the case, contrary to the studies presented. The authors 
use a simultaneous equations model to verify the causality between intra-industry trade and tariffs and conclude that the traditionally-drawn conclusions about intra-industry trade negatively influencing the rates at which tariffs are set, are estimated using models in which only one equation is estimated. When two estimates are performed simultaneously, as the authors did, using Australia as an example, the causality is reversed and the negative relationship reported previously does not appear. The authors recommend doing more estimations and tests before advocating that the intra-industry trade is more conducive to liberalization of trade between countries. Menon and Dixon (1996) seek to answer the question opposite to that posed in the preceding paragraphs - do regional trade agreements promote intra-industry trade? - reaching a significant and positive response, for Australia and New Zealand. Foster and Stehrer (2011) use empirical data for the period 1962 - 2000 and a sample of 168 countries, to answer a question similar to that proposed by Menon and Dixon (1996) - what is the effect of preferential trade agreements on the structure of trade? The answer indicates that the inclusion of a country in these arrangements increases the weight of intra-industry trade. However, the effect is greater in high-income countries.

Also related to our work, Jørgensen and Schröder (2005) use a theoretical model to evaluate the effects on the welfare of Ad valorem and specific tariffs in a context where imperfect competition, i.e., the existence of economies of scale, is predominant. They conclude that although we can empirically demonstrate that countries prefer to use $\mathrm{Ad}$ valorem tariffs, as is the case in the two regions that we analyze in this work, the welfare cost to the consumer is lower for specific tariffs. The authors recommend that the type of tariff to be chosen should take into account the characteristics of the sector in which it will be applied, especially in terms of market structure and the ease of market entry and exit by firms.

Based on this literature, this paper tests the existence of a negative association between intra-industry trade and protectionism, at the empirical level in the USA and the EU, which somehow escaped attention in the literature.

This work has the following structure: In Section 2 we describe the data used and in Section 3 we describe the methodology used for data analysis. In Section 4 we analyze the results and in Section 5 the conclusions are presented.

\section{Empirical Strategy}

\subsection{Data}

We used two databases for this work, which will be described in this section (Note 2). First, we used data regarding tariffs of the USA and EU, excluding the remaining trade policy instruments since these are covered by different legislation and can take many forms. These trade policy instruments are often camouflaged by standards of safety and security of goods and people - especially for the USA, where it is not possible to find a single source of information in which they are compiled, although the information was available for the EU in a single source. To ensure comparability between the two blocs, we will consider only tariffs. However, according to earlier studies cited in the Introduction, for comparison between the two trading blocs, customs tariff is, of all instruments, the one which raises the fewest problems. Therefore, our analysis is not compromised, since we choose the instrument which allows a greater degree of comparability.

Data for the tariffs were taken from the customs tariff of each country/region for the year 2009. (Note 3) The customs tariff includes 5052 groups of commodities, divided between sections and chapters, identified by a 6-digit code under the Harmonized System (HS), systematically ranked by order of progressive complexity, taking into account their degree of finish or their position in the manufacturing process. The 6-digit classification of goods is common to all countries that are part of the World Trade Organization (WTO), unlike the 8-digit classification, in which the classification is different. Thus, for purposes of comparison we chose the 6-digit classification. Chapters 98 and 99 of these customs tariffs are residual, created for specific purposes, specific to each country/region, and are distinct for the USA and EU. Chapter 98 - Complete Industrial Plant - was withdrawn because the additional variables that we used in this analysis - data on imports and exports - have no data for this chapter and it is also residual. For Chapter 99 - Reserved for special uses determined by the competent Community authorities - it was decided to put the code 999999 and tariff rate $0 \%$, since it is the rate of most tariffs applied in this chapter for both regions.

The customs tariffs of these two regions can be classified as Ad valorem or specific. The first takes the form of a tax as a percentage of the value of imports of the product. So if the world price is $P^{*}$ and the Ad valorem rate is $t$, the domestic price of imported goods will be $P^{d o m}=P^{*}(1+t)$. Ad valorem tariffs have been subject to progressive reductions in the negotiations of the WTO. Specific tariffs are a fixed rate per unit imported (ton, square meter, or 
other unit of measure), regardless of the monetary value of this unit. So if the world price is $P^{*}$ and if the rate is $t^{\prime}$, the domestic price is $P^{d o m}=P^{*}+t^{\prime}$.

Second, we used data on exports and imports, hereinafter designated respectively by $X$ and $F$, at current prices for the USA, EU, and the total for the World for 2009, disaggregated by 6-digit product codes. The data for the EU came from the database Export Help Desk, from the Export Trade database of the European Commission, from which we took data for exports and imports from the EU-27 to extra EU-27 partners. (Note 4) For the USA and the total for the World, we use the COMTRADE database. (Note 5)

The statistical value, which is used for data on exports and imports, is the value calculated at the national borders. The import values are registered with the CIF value of the goods (Cost, Insurance, and Freight - include the transaction value of the goods and the value of services performed to deliver goods from the border of the exporting country to the border of the importing country), and the values for exports are registered with the FOB value of the goods (Free on Board - include the transaction value of the goods and the value of services performed to deliver the goods to the border of the exporting country).

As mentioned above, there are no statistics for the values of imports and exports of Chapter 98, since this chapter Complete Industrial Plant - is used only in very exceptional cases.

\subsection{Indicators of International Trade}

In order to delve a bit deeper in the analysis, we calculated the following indicators relative to 2009:

- Share of exports $(X)$ and imports $(F)$ of each product in total of exports and in the total of imports, respectively: For exports $=\left(\frac{X_{j i}}{X_{i}}\right)$ for product $j$ in country $i$, and for imports $=\left(\frac{F_{j i}}{F_{i}}\right)$ for product $j$ in country $i$. It allows us to assess which products have the greatest weight in exports and imports.

- Coverage rate of exports: $\left(\frac{X_{j}}{F_{j}}\right)$ is the ratio between exports and imports of a given product, indicating the percentage of imports that is covered by exports. A coverage rate of more than 1 (or $100 \%$ if expressed as a percentage) means that the country has a strong commercial position or trade competitiveness in terms of product $j$, while a rate of less than 1 indicates a weak trading position or trade dependence of that product (negative trade balance in that product).

- Revealed Comparative Advantages Index: $(R C A)_{j}=\frac{\left(\frac{x_{j i}}{X_{i}}\right)}{\left(\frac{x_{j p}}{X_{p}}\right)}$, for each product $j$, where $i$ is the country's index and $\mathrm{p}$ is the region of comparison's index. RCA measures the intensity of specialization in international trade of a country relative to a region or to the world. If the RCA is greater than 1, the country reveals comparative advantage for exports of a particular product, i.e., this country is relatively specialized in the export of this good. On the other hand, if the RCA is less than 1 , the country does not reveal comparative advantage in the export of that product.

- Grubel-Lloyd Index: $(G L)_{j}=\frac{\left(X_{j}+F_{j}\right)-\left|X_{j}-F_{j}\right|}{\left(X_{j}+F_{j}\right)}$. This indicator measures the proportion of intra-industry trade in a given product, ranging between 0 and 1 . If $G L_{j}=1$ there is only intra-industry trade, while if $G L_{j}=0$ there is only inter-industry trade.

\subsection{Cluster Analysis}

In this section we describe the methodology used in this work. Given the goal of this study - to analyze the Customs Tariff of the USA and the EU, in order to find patterns within each customs tariff that could be related to the type of trade (intra or inter) and also to compare the two customs tariffs - the methodological strategy followed was supported by Cluster Analysis.

We had several indicators to identify patterns within each region - share of exports, share of imports, coverage rate of exports, RCA index , GL index (all quantitative variables), and also the tariff (a variable categorized as Ad valorem or specific). 
After an exploratory analysis of the quantitative variables, we concluded (with the exception of the GL index) that they were strongly asymmetric. Tests of asymmetry were performed and the $Z$ statistics obtained widely exceed the range $[-2 ; 2]$ considering a $5 \%$ level of significance.

We therefore decided to perform the clustering using only the GL index, in the case of quantitative variables. The remaining variables were then used to characterize the clusters, hence, we aim to identify the structure of the relation between the variables, within each cluster.

The variable tariff was initially considered as an input for clustering. This variable was categorized as Advalorem or specific tariffs, and therefore had to be treated as a qualitative variable. This was not a problem because the two-step cluster analysis performs well with simultaneously quantitative and qualitative variables. A problem arises from the fact that tariffs have a very large number of categories - 252 for the EU and 395 for the USA - making it statistically inoperable to build clusters and consequently to find patterns.

Through a hierarchical cluster analysis we grouped the products according to the GL index, separately for USA and for EU. In order to obtain a robust solution we held the clustering aggregation using three methods - the ward method, the furthest neighbor method, and the centroid method.

Comparing the clustering results, a four cluster solution was fixed and an optimization method (K-Means) was then used in order to perform the final segmentation of the GL index in both universes in review. By Cramer's V there was a strong association between solutions obtained via the hierarchical methods and the optimization method (K-means): the minimum and maximum value for the USA is respectively 0.726 and 0.892 , while for the EU is 0.774 and 0.894 .

\section{Results}

In this section we analyze the results obtained from the cluster analysis, having used the GL Index as a grouping variable and the remaining variables as characterizing the clusters founded. (Note 6, Note7)

\subsection{USA}

In this section we analyze the results obtained with cluster analysis for the USA. The evidence presented allows us to draw several important conclusions. All four clusters are relatively similar in size, as shown in Table 1. Clusters 3 and 2 are the first and second cluster respectively with the highest values for the GL index (0.882 and 0.631) and above the USA average (0.503). Clusters 4 and 1 present the lowest values for the GL index (0.108 and 0.108) and below the USA average.

Table 1 shows the ranking of the sectors (chapters in the terminology of the combined nomenclature) by cluster, taking into account the relative position of the sectors which weight at least $2 \%$ in cluster 3 - the cluster in which the GL Index is higher. (Note 8) The remaining sectors that appear in the table were then taken from cluster 2, then cluster 1, and then cluster 4, if they did not appear in cluster 3 by the criteria established but appear on the other clusters by the same criteria. In this way we can compare all of the sectors in all of the clusters that represent at least $2 \%$ in the cluster and compare their relative positions in the other clusters, even if their weight is less than $2 \%$.

Table 1. Ranking of the sectors relative to Cluster 3 for the USA (sectors that weight at least 2\%)

\begin{tabular}{|c|c|c|c|c|c|c|c|c|}
\hline \multirow[t]{2}{*}{ Sector } & \multicolumn{2}{|c|}{$\begin{array}{l}\text { Cluster } 1 \\
(\mathrm{~N}=1135)\end{array}$} & \multicolumn{2}{|c|}{$\begin{array}{l}\text { Cluster } 2 \\
(\mathrm{~N}=1292)\end{array}$} & \multicolumn{2}{|c|}{$\begin{array}{l}\text { Cluster } 3 \\
(\mathrm{~N}=1309)\end{array}$} & \multicolumn{2}{|c|}{$\begin{array}{l}\text { Cluster } 4 \\
(\mathrm{~N}=1302)\end{array}$} \\
\hline & Rank & Weight & Rank & Weight & Rank & Weight & Rank & Weight \\
\hline 84 & 1 & 8.2 & 1 & 12.8 & 1 & 16.4 & 8 & 2.5 \\
\hline 85 & 3 & 4.3 & 2 & 6.3 & 2 & 8.3 & 14 & 1.8 \\
\hline 29 & 2 & 6.7 & 3 & 6.1 & 3 & 5.8 & 1 & 7.8 \\
\hline 72 & 6 & 3.1 & 5 & 3.7 & 4 & 4.0 & 9 & 2.4 \\
\hline 90 & 8 & 2.8 & 4 & 4.8 & 5 & 3.7 & 63 & 0.5 \\
\hline 73 & 10 & 2.3 & 8 & 2.9 & 6 & 3.7 & 29 & 1.1 \\
\hline 28 & 4 & 4.1 & 7 & 3.1 & 7 & 3.1 & 6 & 2.8 \\
\hline 48 & 12 & 2.1 & 10 & 2.4 & 8 & 2.7 & 28 & 1.1 \\
\hline
\end{tabular}




\begin{tabular}{crrrrrrrr}
$\mathbf{3 9}$ & 7 & 2.9 & 6 & 3.4 & 9 & 2.4 & 22 & 1.3 \\
$\mathbf{4 0}$ & 14 & 2.0 & 12 & 1.8 & 10 & 2.1 & 36 & 0.9 \\
$\mathbf{8 7}$ & 27 & 1.1 & 19 & 1.3 & 11 & 2.0 & 20 & 1.5 \\
$\mathbf{5 5}$ & 9 & 2.6 & 9 & 2.6 & 15 & 1.5 & 12 & 1.9 \\
$\mathbf{5 2}$ & 5 & 3.1 & 11 & 2.0 & 12 & 1.8 & 5 & 3.1 \\
$\mathbf{3}$ & 11 & 2.2 & 32 & 0.9 & 31 & 0.8 & 4 & 4.5 \\
$\mathbf{6 2}$ & 22 & 1.4 & 35 & 0.8 & 55 & 0.4 & 2 & 6.3 \\
$\mathbf{6 1}$ & 25 & 1.1 & 18 & 1.4 & 35 & 0.8 & 3 & 5.0 \\
$\mathbf{2}$ & 43 & 0.6 & 46 & 0.6 & 52 & 0.4 & 7 & 2.7 \\
$\mathbf{4 4}$ & 18 & 1.7 & 26 & 1.1 & 24 & 1.1 & 10 & 2.2 \\
\hline Sectors & $14,97,99$ & \multicolumn{7}{c}{$80,79,67,66}$, \\
with 0\%
\end{tabular}

Note: The designation of the sectors are the following: 2 - Meat and edible meat offal, 3 - Fish and crustaceans, molluscs, and other aquatic invertebrates, 28 - Inorganic chemicals: organic or inorganic compounds of precious metals, of rare--earth metals, of radioactive elements, or of isotopes, 29 - Organic chemicals, 39 - Plastics and articles thereof, 40 - Rubber and articles thereof, 44 - Wood and articles of wood; wood charcoal, 48 - Paper and paperboard; articles of paper pulp, of paper, or of paperboard, 52 - Cotton, 53 - Other vegetable textile; paper yarn and woven fabrics of paper yarn, 61 - Articles of apparel and clothing accessories, knitted or crocheted, 62 - Articles of apparel and clothing accessories, not knitted or crocheted, 72 - Iron and steel, 73 - Articles of iron or steel, 84 Nuclear reactors, boilers, machinery, and mechanical appliances; parts thereof, 85 - Electrical machinery and equipment and parts thereof; sound recorders and reproducers, television image and sound recorders and reproducers, and parts and accessories of such articles, 87 - Vehicles other than railway or tramway rolling--stock, and parts and accessories thereof, 90 - Optical, photographic, cinematographic, measuring, checking, precision, medical or surgical instruments and apparatus; parts and accessories thereof.

For clusters 1 to 3 , sectors 29,84 , and 85 are the most representative ones, and also sectors 28 and 72 to a lesser extent. In cluster 4, only sector 29 is among the five most representative sectors. Clusters 3 and 2 are the ones that share a more similar structure, then cluster 1 , and finally cluster 4 . Most of the sectors that appear as important in cluster 4 are residual in the other clusters, like sectors 62, 61, 3, 52, 2, and 44.

There are sectors that do not appear in some clusters ( $0 \%$ weight) but are important in others (Note 9), like sector 36, which has a $0.4 \%$ weight in cluster 1 , sector 49 , which is relatively important in clusters 3 and 1 ( $0.6 \%$ weight), sector 50 in cluster 1 (it is worth $0.4 \%)$, sector 65 in cluster 1 ( $0.5 \%$ of weight), sectors $66(0.4 \%)$ and $67(0.5 \%)$ in cluster 4 , and finally sector 97 in cluster 3 ( $0.5 \%$ of weight). In order to obtain further insights in this discussion, we consider the taxonomy proposed by Peneder (2001), according to which the sectors are classified as "mainstream", labor intensive", "capital intensive", "marketing driven", and "technology driven" industries. (Note 10) According to this taxonomy, we verified that the most important sectors in clusters 3, 1, and 2 are mainly technology driven (and in some cases capital intensive), while some of the most important sectors in cluster 4 are labor intensive or mainstream.

As can be seen in Table 2, the cluster where the rate $0 \%$ is most frequent is cluster 3, in which the GL index is higher and the cluster in which the proportion of this rate is lower is cluster 4, the cluster with the smallest value for the GL index. In this table tariffs are ranked by their weight in the cluster and we show only those weights greater than or equal to $1 \%$. The Ad valorem rates more representative in clusters where the GL index is higher, are lower on average than in the clusters where the GL index is lower. The application of a given rate is, for almost all cases, independent of cluster formation - for example, the rate of $3.7 \%$ is always applied to sectors 28 and 29, although in cluster 4 it is also applied to sectors 37 and 38; the rate of $6.5 \%$ is always applied to sectors 29 and 39; the rate of $2.5 \%$ is always applied to sectors $40,84,85$, and 87 . The RCA index reveals no clear pattern in the products taxed with the rates mentioned, and can be below or above 1 . 
Table 2. Weight of tariffs in each cluster for the USA (tariffs that weight at least 1\%)

\begin{tabular}{|c|c|c|c|c|c|c|c|}
\hline \multicolumn{2}{|c|}{ Cluster 1} & \multicolumn{2}{|c|}{ Cluster 2} & \multicolumn{2}{|c|}{ Cluster 3} & \multicolumn{2}{|c|}{ Cluster 4} \\
\hline Tariff & Weight & Tariff & Weight & Tariff & Weight & Tariff & Weight \\
\hline Ad val. (3.7\%) & 4.5 & Ad val. $(3.7 \%)$ & 3.3 & Ad val. (3.7\%) & 3.5 & Ad val. $(6.5 \%)$ & 3.2 \\
\hline Ad val. (6.5\%) & 2.9 & Ad val. $(6.5 \%)$ & 2.8 & Ad val. $(6.5 \%)$ & 2.7 & Ad val. $(3.7 \%)$ & 2.7 \\
\hline Ad val. (3\%) & 2.1 & Ad val. $(2.5 \%)$ & 2.4 & Ad val. (2.5\%) & 2.5 & Ad val. (5.5\%) & 2.5 \\
\hline Ad val. (5\%) & 1.7 & Ad val. (3\%) & 1.8 & Ad val. (3\%) & 2.4 & Ad val. (16\%) & 1.5 \\
\hline Adval. $(2.5 \%)$ & 1.7 & Ad val. (5.5\%) & 1.6 & Ad val. $(2.7 \%)$ & 2.1 & Ad val. $(10 \%)$ & 1.3 \\
\hline Ad val. $(14.9 \%)$ & 1.6 & Ad val. $(2.7 \%)$ & 1.6 & Ad val. (5\%) & 1.8 & Ad val. (6.4\%) & 1.2 \\
\hline Adval. $(4.2 \%)$ & 1.5 & Ad val. $(4.2 \%)$ & 1.5 & Ad val. $(3.1 \%)$ & 1.8 & Ad val. $(6 \%)$ & 1.2 \\
\hline Ad val. (5.5\%) & 1.1 & Ad val. (5\%) & 1.3 & Ad val. $(4.4 \%)$ & 1.7 & Adval. (14\%) & 1.1 \\
\hline Ad val. (4\%) & 1.1 & Ad val. $(3.3 \%)$ & 1.3 & Ad val. $(4.2 \%)$ & 1.7 & Ad val. $(14.9 \%)$ & 1.0 \\
\hline Ad val. (12\%) & 1.0 & Ad val. $(14.9 \%)$ & 1.2 & Ad val. $(14.9 \%)$ & 1.5 & Ad val. $(5 \%)$ & 1.0 \\
\hline Ad val. $(10 \%)$ & 1.0 & Ad val. $(4.4 \%)$ & 1.2 & Ad val. $(5.5 \%)$ & 1.1 & Ad val. (3\%) & 1.0 \\
\hline \multirow[t]{5}{*}{ Ad val. $(6 \%)$} & 1.0 & Ad val. (4\%) & 1.1 & Ad val. $(3.9 \%)$ & 1.1 & & \\
\hline & & Ad val. $(12 \%)$ & 1.0 & Ad val. (2.8\%) & 1.1 & & \\
\hline & & Ad val. $(6 \%)$ & 1.0 & Ad val. $(3.8 \%)$ & 1.0 & & \\
\hline & & Ad val. (5.3\%) & 1.0 & & & & \\
\hline & & Ad val. $(3.1 \%)$ & 1.0 & & & & \\
\hline Free & 40.7 & Free & 40.5 & Free & 43 & Free & 37.3 \\
\hline
\end{tabular}

Figure 1 shows a characterization of the additional international trade indicators - share of exports, share of imports, coverage rate of exports, and the revealed comparative advantage (RCA) index in the four clusters. The two indicators that allow us to differentiate between clusters are the RCA index and the coverage rate of exports. The evidence shows that the coverage rate of exports and the RCA index are the ones that are more differentiated between clusters (when we analyze the median). Cluster 4 is the most different concerning all four indicators. In the clusters there are some products which are extreme outliers, i.e., record values for the indicators very different from what is the median for each cluster. (Note 11) Clusters 1 and 4 show a greater proportion of products that have extreme outliers in the four characterization indicators.

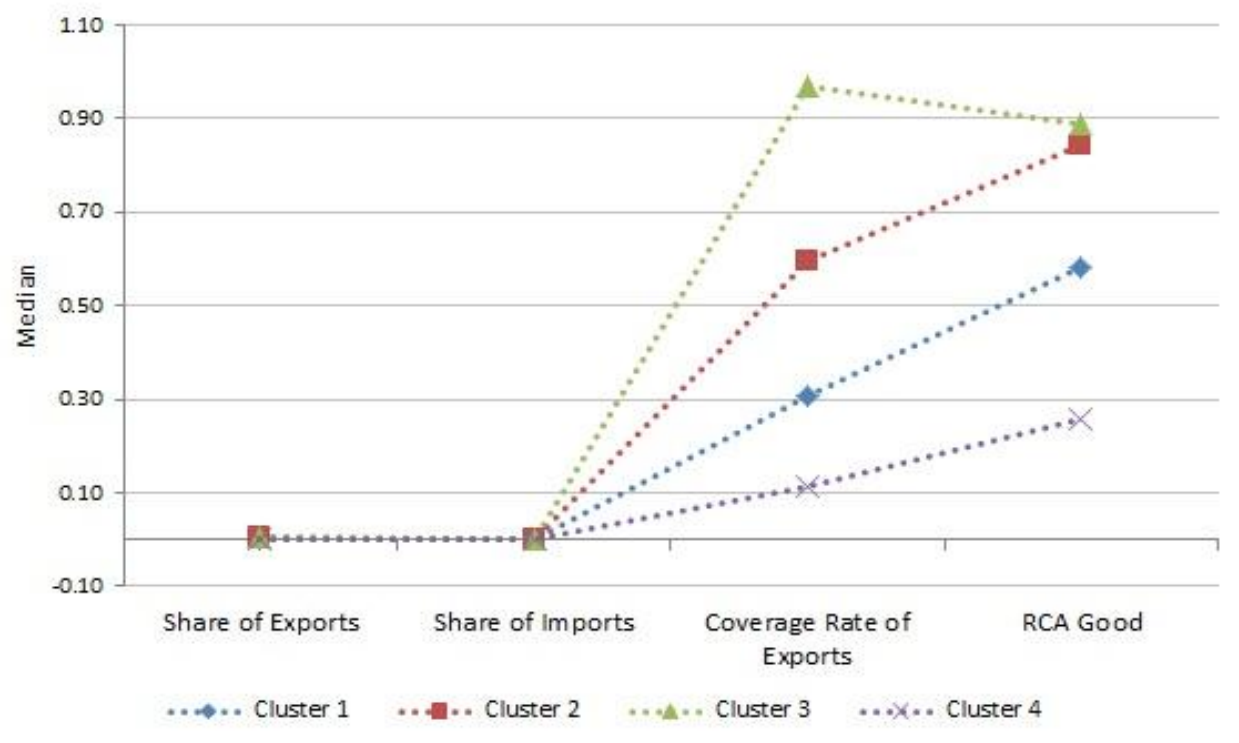

Figure 1. Median of the four international indicators - USA

Note: We use the median for this Figure due to the extreme asymmetry of the international trade indicators. 
The clusters in which the GL is lower are also those in which the maximum value for the RCA index is higher, revealing a behavior that agrees with what is expected at an interindustry level, although the percentage of products that have a revealed comparative advantage is higher in clusters 3 and 2 (43.09\% and 41.8\%, respectively).

Table 3 shows the correlations among the four additional indicators that assist in the characterization of clusters after these have been grouped by GL, and also between the GL and the four indicators. We calculated the coefficient correlation of Spearman's Rho due to the extreme asymmetry of the indicators in almost all clusters. These results suggest that the higher the GL index, the higher the correlation between the share of exports and the share of imports and also the correlation between the RCA index and the share of imports. The (negative) correlation between the coverage rate of exports and the share of imports is smaller in this case. In clusters where the GL index is lower, results suggest that the correlation between the RCA index and the share of exports is higher and also the correlation between the RCA index and the coverage rate of exports, and the correlation between the coverage rate of exports and the share of exports. The correlations between the GL index and the other indicators are higher (although still low) in clusters in which the GL index is lower.

Table 3. Correlation between the international trade indicators in each cluster in the USA

\begin{tabular}{|c|c|c|c|c|}
\hline Cluster 1 & $\begin{array}{l}\text { Share of } \\
\text { Imports }\end{array}$ & $\begin{array}{c}\text { Coverage Rate of } \\
\text { Exports }\end{array}$ & RCA Good & GL Good \\
\hline Share of Exports & $0.747 * * *$ & $0.301 * * *$ & $0.603 * * *$ & $0.115^{* * *}$ \\
\hline Share of Imports & & $-0.314 * * *$ & $0.146^{* * *}$ & $0.060^{*}$ \\
\hline Coverage Rate of Exports & & & $0.601 * * *$ & $0.194 * * *$ \\
\hline RCA Good & & & & $0.117 * * *$ \\
\hline Cluster 2 & $\begin{array}{l}\text { Share of } \\
\text { Imports }\end{array}$ & $\begin{array}{c}\text { Coverage Rate of } \\
\text { Exports }\end{array}$ & RCA Good & GL Good \\
\hline Share of Exports & $0.906^{* * *}$ & $0.214 * * *$ & $0.535^{* * *}$ & 0.031 \\
\hline Share of Imports & & $-0.167 * * *$ & $0.332 * * *$ & 0.025 \\
\hline Coverage Rate of Exports & & & $0.471 * * *$ & $0.048^{*}$ \\
\hline RCA Good & & & & 0.010 \\
\hline Cluster 3 & $\begin{array}{l}\text { Share of } \\
\text { Imports }\end{array}$ & $\begin{array}{c}\text { Coverage Rate of } \\
\text { Exports }\end{array}$ & RCA Good & GL Good \\
\hline Share of Exports & $0.989^{* * *}$ & 0.034 & $0.463 * * *$ & -0.011 \\
\hline Share of Imports & & $-0.101 * * *$ & $0.442 * * *$ & -0.013 \\
\hline Coverage Rate of Exports & & & $0.134 * * *$ & $0.050^{*}$ \\
\hline RCA Good & & & & 0.021 \\
\hline Cluster 4 & $\begin{array}{l}\text { Share of } \\
\text { Imports }\end{array}$ & $\begin{array}{c}\text { Coverage Rate of } \\
\text { Exports }\end{array}$ & RCA Good & GL Good \\
\hline Share of Exports & $0.295^{* * *}$ & $0.486^{* * * *}$ & $0.619 * * *$ & $0.158 * * *$ \\
\hline Share of Imports & & $-0.620 * * *$ & $-0.319 * * *$ & $0.266^{* * *}$ \\
\hline Coverage Rate of Exports & & & $0.797 * * *$ & $0.094 * * *$ \\
\hline RCA Good & & & & $0.074 * * *$ \\
\hline
\end{tabular}

To sum up, the results for the USA suggest an empirical relationship between intra-industry trade and protectionism, as clusters that have a higher value for the GL index have on average lower tariff rates. 


\section{$3.2 E U$}

In this section we analyze the results for the EU. For ease of comparison between the two sections we will follow the same order in the analysis. The four clusters are similar in size, as can be seen in Table 4. Clusters 1 and 3 are the first and second cluster respectively with the highest values for the GL index (0.886 and 0.637) and above the EU average (0.512). Clusters 4 and 2 have the lowest values for the GL index, 0.129 and 0.380, respectively.

Let us consider the evidence shown in Table 4. For clusters 1 to 3, sectors 29, 84, and 85 are the most representative ones, and also sectors 28 and 72 to a lesser extent. In cluster 4, only sectors 29 and 84 are among the five most representative sectors. Clusters 1 and 3 are those that share a more similar structure, then cluster 2, and finally cluster 4. Most of the sectors that appear as important in cluster 4 are residual in the other clusters, like sectors $3,2,61,44$, and 8 . There are sectors that have a weight of $0 \%$ in some clusters but have a significant importance in others (Note 12), like sector 4 , which has a $1.6 \%$ and $0.4 \%$ weight, respectively in clusters 4 and 2 , sector 13 that is relatively important in cluster 1 , sector 46 in cluster 4 ( $0.8 \%$ of weight), sector 67 in cluster 4 ( $0.5 \%$ of weight), and finally sector $78(0.3 \%)$ in cluster 2 . Results regarding the taxonomy proposed by Peneder (2001) are very similar to those obtained for the USA.

Table 4. Ranking of the sectors relative to Cluster 1 for the EU (sectors that weight at least 2\%)

\begin{tabular}{|c|c|c|c|c|c|c|c|c|}
\hline \multirow[t]{2}{*}{ Sector } & \multicolumn{2}{|c|}{$\begin{array}{l}\text { Cluster 1 } \\
(\mathrm{N}=1270)\end{array}$} & \multicolumn{2}{|c|}{$\begin{array}{l}\text { Cluster } 2 \\
(\mathrm{~N}=1342)\end{array}$} & \multicolumn{2}{|c|}{$\begin{array}{l}\text { Cluster } 3 \\
(\mathrm{~N}=1256)\end{array}$} & \multicolumn{2}{|c|}{$\begin{array}{l}\text { Cluster } 4 \\
(\mathrm{~N}=1184)\end{array}$} \\
\hline & Rank & Weight & Rank & Weight & Rank & Weight & Rank & Weight \\
\hline 29 & 1 & 7.4 & 2 & 6.3 & 3 & 5.8 & 2 & 7.3 \\
\hline 84 & 2 & 7.0 & 1 & 12.6 & 1 & 9.4 & 1 & 11.0 \\
\hline 85 & 3 & 6.6 & 3 & 5.2 & 2 & 6.8 & 13 & 1.9 \\
\hline 90 & 4 & 4.8 & 9 & 2.5 & 5 & 3.9 & 55 & 0.5 \\
\hline 72 & 5 & 4.0 & 4 & 3.0 & 7 & 3.1 & 6 & 3.1 \\
\hline 28 & 6 & 3.5 & 5 & 2.8 & 4 & 4.1 & 7 & 2.6 \\
\hline 73 & 7 & 3.2 & 8 & 2.5 & 8 & 2.9 & 33 & 1.1 \\
\hline 55 & 8 & 3.1 & 17 & 1.5 & 9 & 2.6 & 30 & 1.2 \\
\hline 39 & 9 & 2.8 & 10 & 2.4 & 6 & 3.4 & 28 & 1.3 \\
\hline 52 & 10 & 2.6 & 6 & 2.8 & 12 & 2.1 & 9 & 2.3 \\
\hline 54 & 11 & 2.1 & 33 & 1.0 & 14 & 1.9 & 51 & 0.5 \\
\hline 48 & 12 & 2.0 & 11 & 2.2 & 16 & 1.8 & 11 & 2.2 \\
\hline 62 & 24 & 1.3 & 7 & 2.8 & 10 & 2.6 & 10 & 2.3 \\
\hline 40 & 16 & 1.7 & 20 & 1.4 & 11 & 2.2 & 24 & 1.4 \\
\hline 38 & 23 & 1.3 & 12 & 1.9 & 20 & 1.5 & 18 & 1.6 \\
\hline 3 & 22 & 1.3 & 13 & 1.8 & 23 & 1.3 & 3 & 4.2 \\
\hline 2 & 51 & 0.5 & 76 & 0.2 & 57 & 0.4 & 4 & 3.7 \\
\hline 61 & 18 & 1.7 & 15 & 1.8 & 17 & 1.8 & 5 & 3.2 \\
\hline 44 & 49 & 0.6 & 14 & 1.8 & 22 & 1.4 & 8 & 2.3 \\
\hline 8 & 52 & 0.5 & 19 & 1.4 & 59 & 0.4 & 12 & 2.1 \\
\hline $\begin{array}{l}\text { Sectors } \\
\text { with } 0 \%\end{array}$ & 4,14 & $\begin{array}{l}5,66,67, \\
8\end{array}$ & & & & & & \\
\hline
\end{tabular}

Note: The designation of the sectors are the following (we list here only the ones that did not appear in Table 3 ) -8 Edible fruit and nuts; peel of citrus fruits, or melons, 38 - Miscellaneous chemical products, 54 - Man--made filaments; strip and the like of man--made textile materials, 55 - Man--made staple fibers. 
As documented in Table 5, the cluster where the rate $0 \%$ is more represented is cluster 4 , in which the GL index is lower, and the cluster in which the proportion of this rate is lower is cluster 3, the cluster with the second highest value for the GL index. The Ad valorem tariffs do not seem to reveal a clear pattern between the rates and the GL index. The application of a given rate is, for almost all cases, independent of cluster formation - for example, the rate of $1.7 \%$ is always applied to sector 84 , the rate of $5.5 \%$ is always applied to sectors 28 and 29 , the rate of $12 \%$ is always applied to sectors 61,62 , and 63 . The RCA index reveals no clear pattern in the products taxed with the rates mentioned, and can be below or above 1 .

Table 5. Weight of tariffs in each cluster for the EU (tariffs that weight at least 1\%)

\begin{tabular}{|c|c|c|c|c|c|c|c|}
\hline \multicolumn{2}{|c|}{ Cluster 1} & \multicolumn{2}{|c|}{ Cluster 2} & \multicolumn{2}{|c|}{ Cluster 3} & \multicolumn{2}{|c|}{ Cluster 4} \\
\hline Tariff & Weight & Tariff & Weight & Tariff & Weight & Tariff & Weight \\
\hline Ad val. $(2.7 \%)$ & 9.1 & Ad val. $(6.5 \%)$ & 8.7 & Ad val. $(2.7 \%)$ & 9.6 & Ad val. (1.7\%) & 6.8 \\
\hline Ad val. $(6.5 \%)$ & 8.2 & Adval. $(1.7 \%)$ & 8.2 & Ad val. $(6.5 \%)$ & 8.4 & Ad val. $(12 \%)$ & 6.4 \\
\hline Ad val. $(8 \%)$ & 7.7 & Ad val. $(2.7 \%)$ & 7.7 & Ad val. $(8 \%)$ & 7.4 & Ad val. $(6.5 \%)$ & 5.9 \\
\hline Ad val. $(1.7 \%)$ & 4.8 & Ad val. $(8 \%)$ & 6.4 & Ad val. $(1.7 \%)$ & 6.5 & Ad val. $(5.5 \%)$ & 4.5 \\
\hline Ad val. (5.5\%) & 4.6 & Ad val. $(12 \%)$ & 5.7 & Ad val. $(5.5 \%)$ & 4.5 & Ad val. $(2.7 \%)$ & 3.7 \\
\hline Ad val. $(12 \%)$ & 4.1 & Ad val. $(5.5 \%)$ & 4.2 & Ad val. $(12 \%)$ & 4.3 & Ad val. (4\%) & 3.6 \\
\hline Ad val. (4\%) & 4.1 & Ad val. $(4 \%)$ & 4.2 & Ad val. $(3.7 \%)$ & 3.7 & Ad val. (8\%) & 2.9 \\
\hline Ad val. $(3 \%)$ & 2.7 & Ad val. $(3.7 \%)$ & 2.9 & Ad val. (4\%) & 3.6 & Ad val. $(2.2 \%)$ & 1.8 \\
\hline Ad val. $(3.7 \%)$ & 1.1 & Ad val. $(5 \%)$ & 1.6 & Ad val. (5\%) & 1.9 & Ad val. $(3.7 \%)$ & 1.6 \\
\hline Ad val. (4\%) & 1.1 & Ad val. $(2.2 \%)$ & 1.6 & Ad val. (3\%) & 1.9 & Ad val. $(4.7 \%)$ & 1.3 \\
\hline Ad val. $(3.2 \%)$ & 1.7 & Ad val. $(3.2 \%)$ & 1.3 & Ad val. $(2.2 \%)$ & 1.8 & Ad val. $(2 \%)$ & 1.0 \\
\hline Ad val. (5\%) & 1.5 & Ad val. $(2 \%)$ & 1.3 & Ad val. $(3.2 \%)$ & 1.2 & & \\
\hline Ad val. $(2.2 \%)$ & 1.4 & Ad val. $(6 \%)$ & 1.0 & Ad val. $(6 \%)$ & 1.0 & & \\
\hline Adval. $(7.5 \%)$ & 1.2 & Ad val. $(4.7 \%)$ & 1.0 & Ad val. $(4.7 \%)$ & 1.0 & & \\
\hline Ad val. (6\%) & 1.1 & Ad val. $(3 \%)$ & 1.0 & Ad val. $(4.5 \%)$ & 1.0 & & \\
\hline \multirow[t]{2}{*}{ Ad val. $(5.3 \%)$} & 1.1 & & & Ad val. $(3.5 \%)$ & 1.0 & & \\
\hline & & & & Ad val. $(2 \%)$ & 1.0 & & \\
\hline Free & 24.4 & Free & 24.4 & Free & 23.4 & Free & 30.2 \\
\hline
\end{tabular}

Concerning the four characterization indicators (Figure 2), the coverage rate of exports is the only indicator that is more differentiated between clusters (when we analyze the median). Cluster 4 is the most different concerning all four indicators. Clusters 2 and 4 show a greater proportion of products that have extreme outliers in the four characterization indicators, except for the RCA index.

Clusters 2 and 3 have the highest percentage of products with a revealed comparative advantage higher than 1 (48.66\% and $46.5 \%$, respectively). The relationship between the GL index and the RCA index does not seem to follow any clear pattern.

The results shown in Table 6 suggest that the higher the GL index, the higher the correlation between the share of exports and the share of imports and also the correlation between the RCA index and the share of imports. The (negative) correlation between the coverage rate of exports and the share of imports is smaller in this case. In clusters where the GL index is lower, results suggest that the correlation between the RCA index and the share of exports is higher and also the correlation between the RCA index and the coverage rate of exports, and the correlation between the coverage rate of exports and the share of exports. The correlations between the GL index and the other indicators are higher (although still low) in clusters in which the GL index is lower. 


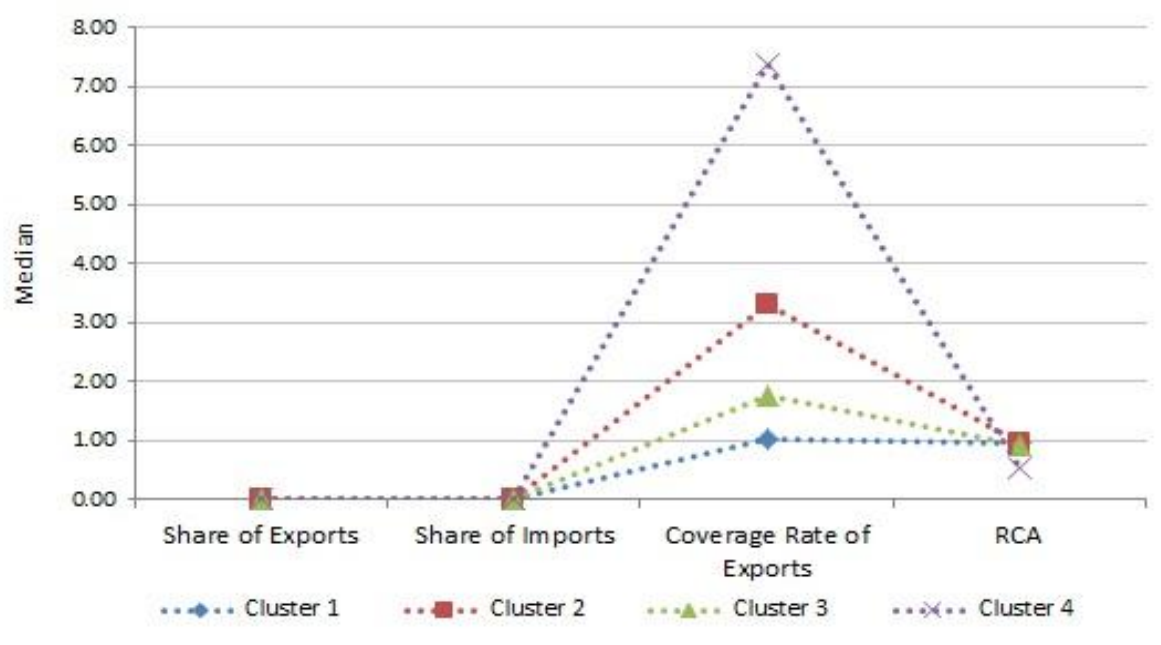

Figure 2. Median of the four international indicators - EU

Note: We use the median for this Figure due to the extreme asymmetry of the international trade indicators.

Table 6. Correlation between the four indicators in each cluster in the EU

\begin{tabular}{|c|c|c|c|c|}
\hline Cluster 1 & $\begin{array}{l}\text { Share of } \\
\text { Imports }\end{array}$ & $\begin{array}{c}\text { Coverage Rate } \\
\text { of Exports }\end{array}$ & RCA Good & GL Good \\
\hline Share of Exports & $0.987 * * *$ & $0.137 * * *$ & $0.316^{* * *}$ & $-0.063 *$ \\
\hline Share of Imports & & -0.009 & $0.279 * * *$ & $-0.061 *$ \\
\hline Coverage Rate of Exports & & & $0.239 * * *$ & -0.046 \\
\hline RCA Good & & & & -0.043 \\
\hline Cluster 2 & $\begin{array}{l}\text { Share of } \\
\text { Imports }\end{array}$ & $\begin{array}{l}\text { Coverage Rate } \\
\text { of Exports }\end{array}$ & RCA Good & GL Good \\
\hline Share of Exports & $0.718 * * *$ & $0.362 * * *$ & $0.542 * * *$ & $0.066 * *$ \\
\hline Share of Imports & & $-0.285^{* * *}$ & 0.021 & $0.073^{* *}$ \\
\hline Coverage Rate of Exports & & & $0.670 * * *$ & $-0.149 * * *$ \\
\hline RCA Good & & & & $0.049 *$ \\
\hline Cluster 3 & $\begin{array}{l}\text { Share of } \\
\text { Imports }\end{array}$ & $\begin{array}{c}\text { Coverage Rate } \\
\text { of Exports }\end{array}$ & RCA Good & GL Good \\
\hline Share of Exports & $0.901 * * *$ & $0.281 * * *$ & $0.399 * * *$ & -0.005 \\
\hline Share of Imports & & $-0.105^{* * *}$ & $0.171 * * *$ & 0.034 \\
\hline Coverage Rate of Exports & & & $0.556 * * *$ & $-0.217 * * *$ \\
\hline RCA Good & & & & -0.041 \\
\hline Cluster 4 & $\begin{array}{l}\text { Share of } \\
\text { Imports }\end{array}$ & $\begin{array}{c}\text { Coverage Rate } \\
\text { of Exports }\end{array}$ & RCA Good & GL Good \\
\hline Share of Exports & $0.227 * * *$ & $0.563^{* * *}$ & $0.689 * * *$ & $0.240 * * *$ \\
\hline Share of Imports & & $-0.587 * * *$ & $-0.294 * * *$ & $0.278^{* * *}$ \\
\hline Coverage Rate of Exports & & & $0.781 * * *$ & -0.045 \\
\hline RCA Good & & & & $0.175^{* * *}$ \\
\hline
\end{tabular}


Given the results, the relationship between the degree of intra-industry trade and the level of protectionism found in economic theory, does not seem to fit the European case. This conclusion for the case of the EU, should be interpreted cautiously, however, as the empirical exercise conducted in this case considers only the extra-EU trade. Therefore, the intra-EU trade - the most important one, representing more than $80 \%$ - is not included, which may lead to less robust results.

\subsection{USA - EU Comparison}

In this section we perform a comparative analysis between the two regional economic blocs, given the results presented in the previous two sections.

The value of the GL index is very similar to the two regions - 0.512 and 0.503 respectively for the EU and the USA and the values found for the clusters are also similar, although the order in which they appear are different, as can be seen in Figure 3.

The clusters' sectoral compositions are similar for clusters 1 to 3 in both the USA and the EU, with the predominance of sectors 29,84 , and 85 , and also 28 and 72 in a lesser extent, although the ranking position in the cluster is not the same (but very similar). Cluster 4 is different in both cases, and only sector 29 (in the case of the USA) and 29 and 84 (in the EU) are common to the other clusters. In the USA the most representative sectors of cluster 4 (which are residual in the other clusters) include 62,61,3,52, 2, and 44, and in the EU include 3, 2, 61, 44, and 8. Therefore, cluster 4 shows a higher degree of dissimilarity, in terms of sectoral composition, both within and between the USA and the EU. Even so, sectors 52 and 62 are still representative in other EU clusters. Sector 8 for the EU is the only one specific. In both regions sectors 14, 80, and 99 are almost nonexistent in all clusters. Sectors 66 and 97 are irrelevant in all EU clusters but not in all of the USA clusters, and sectors 45 and 79 are irrelevant in all USA clusters and also have a small weight in all EU clusters.

When we apply the taxonomy proposed by Peneder (2001), we verify that the results are consistent for the two cases under analysis. Specifically, clusters in which the GL index is lower are mainly labor intensive or mainstream, while clusters in which the GL is higher are predominantly technology driven or capital intensive.

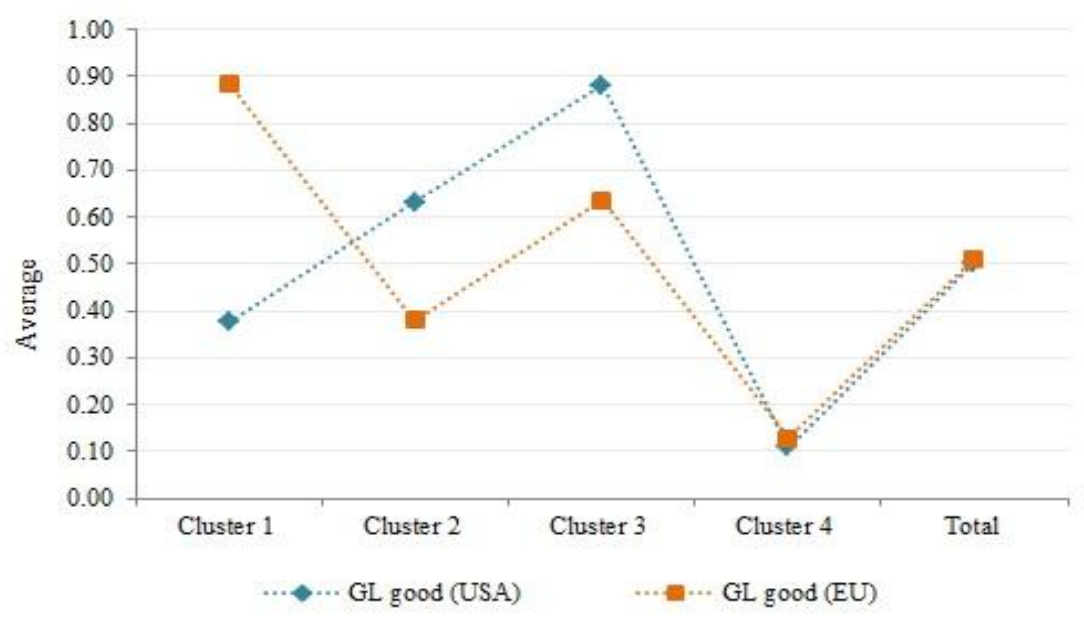

Figure 3. Average for the GL of Goods for the USA and the EU

Additionally, it should be noted that the USA Customs Tariff is less protectionist than the European, registering a much higher percentage of products in which the rate of customs duty is $0 \%$ and noting also that Ad valorem rates are on average always lower (and smaller in terms of weight). These findings are in line with those reported by Bouët et al. (2008) and also Guimbard et al. (2012), discussed in the Introduction. In the USA the clusters with a higher GL index have, on average, lower Ad valorem tariff rates (the more representative ones) and also a larger proportion of $0 \%$ tariff rate. In the EU, the tariff rates do not seem to reveal a clear pattern of relationship with the GL index. For both the USA and the EU the application of a given tariff rate is independent of cluster formation, but not of sectors. Also, in both economic regions the RCA index reveals no clear pattern in the products taxed and its relationship with the tariff rates. 
For the USA the coverage rate of exports and the RCA index are indicators that distinguish very well between clusters, but for the EU only the coverage rate of exports allows the distinction between clusters. Additionally, the coverage rate of exports for the EU is much higher in all clusters than the ones found for the USA, as seen in Figure 4. The indicators share of exports and share of imports do not show very distinctive characteristics. The median of the coverage rate of exports for the EU shows significant changes between the four clusters, ranging from 1 to 7.5. On the other hand, the same indicator for the USA shows very similar values, in the range of 0 to 1 . Cluster 4 in both regions is the cluster that stands out in terms of the international trade indicators. The clusters with a large proportion of extreme outliers are those where the GL index is lower, for both regions.

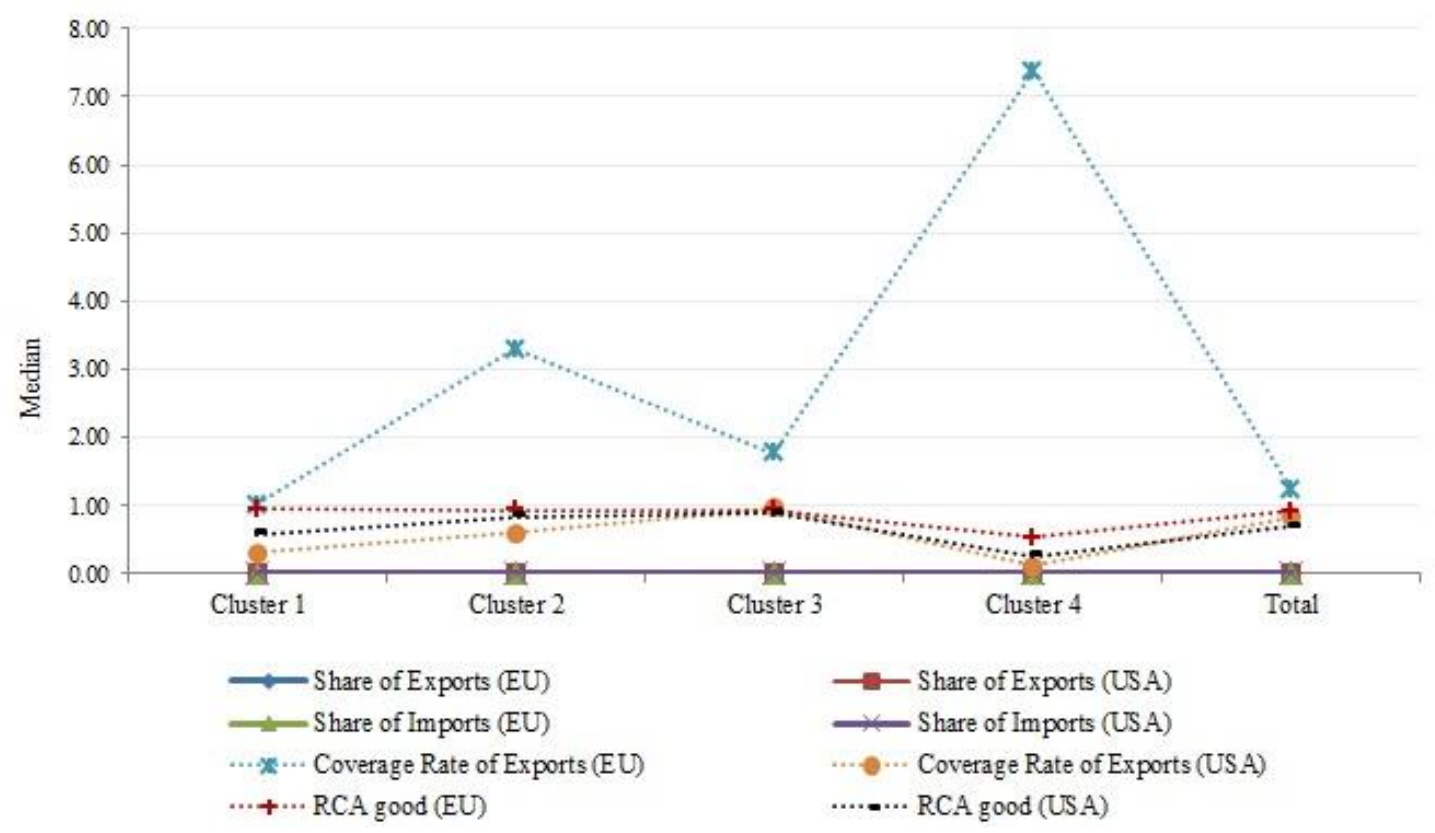

Figure 4. Median of the four international trade indicators for the USA and the EU

The proportion of products in all clusters for the EU that have an RCA index of more than one is much higher than in the USA, standing between $42.6 \%$ and $48.7 \%$ of the products, while for the USA the range is between $31.8 \%$ and $43.1 \%$. In the USA, when the GL index is lower in the cluster the RCA index is higher, but in the EU this relationship is not very clear.

Additionally, in the two regions, the higher the value for the GL index, the higher the correlation between the share of exports and the share of imports weight, which is obvious because of the way the GL index is calculated. Also, the higher the GL index, the lower the (negative) correlation between the share of imports and the coverage rate of exports, becoming almost zero, because when there is intra-industry trade, imports and exports can have similar shares.

Finally, according to what has been discussed above, the USA seems to have a relationship between intra-industry trade and protectionism, more conniving with economic theory, while for the EU the results are not conclusive.

\section{Conclusion}

The literature on trade protectionism has claimed that the level of trade protectionism is lower in countries that present a higher degree of intra-industry trade, since countries that sell substitute goods may easily engage in trade wars. Based on this literature, this paper tested the existence of a negative association between intra-industry trade and protectionism, at the empirical level in the USA and the EU, two of the largest economic regions in the World, which somehow escaped attention in the literature.

The degree of intra-industry trade in this work was measured by the Grubel-Lloyd (GL) index. This variable was used to perform a cluster analysis, from which we defined four clusters for each region, which were then characterized using the information about the customs' tariffs, as well as additional international trade indicators, 
built with data on exports and imports to and from the world for each of these regions. Cluster analysis has never been used to test this theory before. We draw a comparison between the customs tariffs of two regional economic blocs - the USA and the EU - with respect to the degree of protectionism inherent in them.

The results show a significant difference in the tariffs applied between the USA and the EU, with the USA presenting a lower level of protectionism. Additionally, the results for the USA show a positive relationship between the degree of intra-industry trade and a lower level of protectionism, while for the EU the results are not conclusive, showing therefore that results are case-specific, and more research is needed, in order to assess the robustness of these conclusions, for other spaces and periods.

\section{Acknowledgement}

Alexandra Ferreira-Lopes, Helena Carvalho, and Nuno Crespo acknowledge the support from FCT. The authors would like to thank Francisco Madelino for useful comments, as well as the Editor and an anonymous reviewer. The usual disclaimer applies.

\section{References}

Baldwin, R. (1985). The Political Economy of USA Trade Policy. Cambridge, Massachusetts, MIT Press.

Bohara, A. K., \& W. H. Kaempfer. (1991, March). A Test of Tariff Endogeneity in the United States. American Economic Review, 81(4), 952-960.

Bouët, A., Y. Decreux, L. Fontagné, S. Jean, \& D. Laborde. (2008). Assessing Applied Protection across the World. Review of International Economics, 16(5), 850-863. https://doi.org/10.1111/j.1467-9396.2008.00753.x

Brülhart, M., \& R. J. R. Elliot. (1998). Adjustment to the European Single Market: Inferences from Intraindustry Trade Patterns. Journal of Economic Studies, 25(3), 225-247. https://doi.org/10.1108/01443589810215360

Cipollina, M., \& L. Salvatici. (2008, July). Measuring Protection: Mission Impossible?. Journal of Economic Surveys, 22(3), 577-616. https://doi.org/10.1111/j.1467-6419.2007.00543.x

Clark, D. P. (2002). Intra-Industry Specialization and the North American Free Trade Agreement. The International Trade Journal, 16(4), 393-411. https://doi.org/10.1080/08853900290090845

Foster, N., \& R. Stehrer. (2011). Preferential Trade Agreements and the Structure of International Trade. Review of World Economics, 147, 385-409. https://doi.org/10.1007/s10290-011-0093-y

Greenaway, D., \& R. C. Hine. (1991, December). Intra-Industry Specialization, Trade Expansion and Adjustment in the European Economic Space. Journal of Common Market Studies, 29(6), 603-622. https://doi.org/10.1111/j.1468-5965.1991.tb00411.x

Guimbard, H., S. Jean, M. Mimouni, \& X. Pichot. (2012). MAcMap-HS6 2007, an exhaustive and consistent measure of applied protection in 2007. CEPII WP No. 2012-10. https://doi.org/10.1016/S2110-7017(13)60046-3

Hair, J., R. Anderson, R. Tatham, \& W. Black. (2010). Multivariate Data Analysis: A Global Perspective (7 $7^{\text {th }}$ ed.). Upper Saddle River, Pearson International Edition.

Hufbauer, G. C., \& K. A. Elliot. (1994). Measuring the Costs of Protection in the United States. Washington D.C., Institute for International Economics.

JØrgensen, J. G., \& P. J. H. Schröder. (2005, February). Welfare-ranking Ad valorem and Specific Tariffs under Monopolistic Competition. Canadian Journal of Economics, 38(1), 228-241. https://doi.org/10.1111/j.0008-4085.2005.00277.x

Magee, S. P., W. A. Brock, \& L. Young. (1989). Black Hole Tariffs and Endogenous Policy Theory: Political Economy in General Equilibrium. Cambridge University Press, Cambridge.

Marvel, H. P., \& J. R. Edward. (1987). Intraindustry Trade: Sources and Effects on Protection. Journal of Political Economy, 95(6), 1278-1291. https://doi.org/10.1086/261515

Menon, J., \& P. B. Dixon. (1996). Regional Trading Agreements and Intra-Industry Trade. Journal of Economic Integration, 11(1), 1-20. https://doi.org/10.11130/jei.1996.11.1.1

Messerlin, P. (2001). Measuring the Costs of Protection in Europe: European Commercial Policy in the 2000s. Washington, D.C., Institute for International Economics.

Peneder, M. (2001). Entrepreneurial Competition and Industrial Location. Edward Elgar: Cheltenham, UK. 
Peneder, M. (2003). Industry Classifications: Aim, Scope and Techniques. Journal of Industry, Competition and Trade, 3(1-2), 109-129. https://doi.org/10.1023/A:1025434721292

Ratnayake, R., \& S. Jayasuriya. (1991). Intraindustry Trade and Protection: Which Way does the Causality Go?. Economics Letters, 36(1), 71-76. https://doi.org/10.1016/0165-1765(91)90058-S

Vogiatzoglou, K. (2006). Patterns and Determinants of Intra-Industry Trade within NAFTA. Global Business and Economics Review, 8(3-4), 262-279. https://doi.org/10.1504/GBER.2006.010137

\section{Notes}

Note 1 . The specific rates are usually converted into ad valorem in such studies.

Note 2. The entire data set is available upon request.

Note 3. A detailed description of the tariffs, sections, and chapters of them, can be found in the combined nomenclature of goods associated with the customs tariffs, developed by the World Customs Organization in its International Convention on the Harmonized System (HS) of Commodity Description and Coding System, which came into force on 01/01/1988.

Note 4. The website is http://exporthelp.europa.eu.

Note 5. The database COMTRADE is available at http://comtrade.un.org.

Note 6. Product distribution by cluster and respective tariffs and other international trade indicators associated are available upon request, since tables presenting these results were too large. In the following sections we show tables and figures that summarize the characterization of the clusters.

Note 7. The USA has 14 fewer observations than the EU, due to the impossibility of calculating the GL Index for some products.

Note 8. Hereinafter we use the term Sector in lieu of the term Chapter.

Note 9. Sectors with $0 \%$ weight include: 14 - Vegetable plaiting materials; vegetable products not elsewhere specified or included, 36 - Explosives; pyrotechnic products; matches; pyrophoric alloys; certain combustible preparations, 45 - Cork and articles of cork, 49 - Printed books, newspapers, pictures, and other products of the printing industry; manuscripts, typescripts, and plans, 50 - Silk, 65 - Headgear and parts thereof, 66 - Umbrellas, sun umbrellas, walking-sticks, seat-sticks, whips, riding-crops, and parts thereof, 67 - Prepared feathers and down and articles made of feathers or of down; artificial flowers; articles of human hair, 79 - Zinc and articles thereof, 80 - Tin and articles thereof, 97 - Works of art, collectors' pieces, and antiques, and 99 - (Reserved for special uses determined by the competent Community authorities).

Note 10. For further discussion on the importance of these taxonomies see, for instance, Peneder (2003).

Note 11. A case $\left(y_{i}\right)$ is an outlier if: $Q_{3}+1.5 * I Q R \leq y_{i}<Q_{3}+2 * I Q R$ or $Q_{1}-2 * I Q R<y_{i} \leq Q_{1}-1.5 * I Q R$. A case is an extreme outlier if: $y_{i} \geq Q_{3}+2 * I Q R$ or $y_{i} \leq Q_{1}-2 * I Q R$ and $I Q R=Q_{3}-Q$. IQR is the Inter Quartile Range, i.e., the difference between Quartile 3 and Quartile 1, corresponding to the central 50\% of the distribution. The distribution of severe outliers by cluster and indicator is available upon request, since the lists were too long.

Note 12. These sectors include, and we list only the ones which did not appear in Table 3: 4 - Dairy produce; birds' eggs; natural honey; edible products of animal origin, not elsewhere specified or included, 13 - Lac; gums, resins and other vegetable saps and extracts, 46 - Manufactures of straw, of esparto or of other plaiting materials; basketware and wickerwork, and 78 - Lead and articles thereof. 